\title{
SINDICATOS EN CIUDAD JUÁREZ: HISTORIA Y DEBILIDAD SINDICAL
}

\author{
Por \\ Cirila Quintero Ramírez*
}

\begin{abstract}
RESUMEN
Este trabajo analiza la evolución del sindicalismo juarense en tres décadas de industria maquiladora. Postula como idea central, la existencia de un debilitamiento sindical en las maquiladoras debido a dos factores centrales: la ausencia de una trayectoria sindical en la región y la persistencia de actividades económicas dependientes de los vaivenes de la economía estadounidense en Ciudad Júrez, y la existencia de un faccionalismo inter e intrasindical de las principales centrales obreras de la localidad, que ha permitido la derrota no sólo de los movimientos oficiales sino independientes. La debilidad sindical también ha conducido a una política de apatía, conformismo y de alta colaboración con los empresarios, que ha convertido al sindicalismo juarense en una expresión de un sindicalismo subordinado, que legitima su estancia en las maquiladoras más por su vinculación con los empresarios que con sus agremiados. Este artículo permite vislumbrar dos escenarios futuros en la localidad juarense: la acentuación de esta conducta sindical, o bien, la desaparición de los sindicatos en las maquiladoras.
\end{abstract}

\begin{abstract}
This work analyzes the evolution of the labor unions in Ciudad Juárez for three decades of the maquiladora industry. Postulates as a main idea, the existence of a weakening of the labor unions in the maquiladoras as a consequence of two central factors: the absence of a labor union trajectory in the region, and the persistence of economical activities in Ciudad Juárez that depend on the American economy, and the existence of a factionalism inter and intralabor union in the main workers associations in the city, that has permitted the defeat of not only the official movements, but the independent ones too. The weakening of the labor unions has also conducted to a policy of apathy, conformity, and of high colaboration with the investors, that has turned the labor unions in Ciudad Juarez into an expression of subordinated labor unions, that legitimates their permanency in the maquiladoras are mostly to their link with investors than with their members. This article allows us to see two future sceneries in the city of Ciudad Juárez: the accentuation of this kind of behavior in labor unions, or the disappearance of labor unions in the maquiladoras.
\end{abstract}

* El Colegio de la Frontera Norte, directora general del Noreste.

N. del E. Este artículo se aprobó en mayo de 1997 para publicarse en Estudios Fronterizos. 


\section{INTRODUCCIÓN}

Este trabajo analiza la evolución del sindicalismo juarense en tres décadas de desarrollo maquilador. A través del estudio del comportamiento sindical en Ciudad Juárez previo a la instalación de maquiladoras, y de la actuación sindical en treinta años de estancia maquiladora, se postula como hipótesis central que la actual debilidad sindical proviene de la ausencia de un sindicalismo premaquilador consolidado, el faccionalismo intra e intersindical y las derrotas perennes de los movimientos sindicales.

El artículo, también enuncia cómo la debilidad sindical se ha traducido en una flexibilidad contractual acentuada en las maquiladoras. Previo a la exposicion, se presentan algunas consideraciones metodológicas en torno al estudio del sindicalismo en las maquiladoras y el lugar que dentro de este comportamiento ocupa el sindicalismo juarense.

\section{EL SINDICALISMO JUARENSE: VARIANTE DEL SINDICALISMO SUBORDINADO ${ }^{1}$}

La hipótesis inicial de una ausencia sindical en las plantas maquiladoras (Carrillo, 1985) o la existencia de organizaciones meramente funcionales (Carrillo, 1988), ha quedado descartada en distintos estudios ${ }^{2}$ al mostrar que el porcentaje de sindicalización en la industria maquiladora se ha mantenido, entre 1979 y 1990, más o menos estable. Se calcula que durante ese lapso, la tasa de sindicalización promedio de las principales ciudades fronterizas ha fluctuado entre $57.6 \%$ y $52.3 \%$ (Williams, 1992:4).

Dada la persistencia sindical en la mayor parte de localidades maquiladoras, habría que analizar qué tipo de organizaciones sindicales son las que estaban predominando al interior de estas plantas. Los distintos estudios realizados en el sector, permiten señalar que existen tres tipos de organizaciones sindicales al interior de las industrias maquiladoras: los sindicatos consolidados en una época de auge económico de la localidad que lograron infiltrarse sin mucho cuestionamiento en las nacientes industrias; los sindicatos creados exprofeso para este tipo de industrias en localidades con presencia sindical, pero sin una organización capaz de absorber o responder a los requerimientos de la naciente industria; y

1 El término de subordinado se asigna en oposición a un sindicalismo dominante que posee el control laboral de la fuerza laboral de una región, tanto al interior como al exterior de la planta; como podría ser el caso de los sindicatos mineros chilenos o argentinos.

2 Para estudios sobre sindicalismo en las maquiladoras ver Gambrill, (1990); Quintero (1992); Carrillo (1988); Williams (1992). 
finalmente, organizaciones sindicales carentes de una trayectoria sindical que aprovecharon la instalación de las recientes industrias para consolidar un poderío regional, mediante el ofrecimiento de una política total de colaboracion y acorde con las necesidades de las maquiladoras. Dado el predominio de organizaciones oficiales, la presencia sindical de movimientos sindicales independientes en la maquila ha sido mínima, pero no inexistente.

La siguiente fase de análisis del sindicalismo maquilador ha versado sobre las características de las organizaciones sindicales. Un primer balance sobre esta temática permite postular que existen dos variantes sindicales bien definidas dentro de las maquiladoras fronterizas mexicanas: el sindicalismo tradicional y el sindicalismo subordinado. ${ }^{3}$

En torno a los posibles factores explicativos de estos comportamientos, se ha postulado que estas variantes están en función del tipo de maquiladora ${ }^{4}$ la historia sindical premaquiladora de cada región. También se ha enunciado que ambos tipos sindicales tienen un dominio geográfico bien definido: el tradicional se sitúa en el noreste mexicano, integrado por las ciudades fronterizas de Coahuila y Tamaulipas; en tanto que, el subordinado está localizado en las principales ciudades del noroeste mexicano, comprendidas por los estados de Baja California, Sonora y Chihuahua.

Finalmente, habría que mencionar que el sindicalismo tradicional y el subordinado no son comportamientos homogéneos, aunque tienen características empíricas que permiten diferenciarlo como pertenecientes a una

3 La categoría de sindicalismo subordinado podría definirse como la organización laboral inserta en una burocracia sindical, que en una fase de reestructuración industrial, adopta y justifica una política liberalizadora de la fuerza laboral y de las derechos obreros en favor de los requerimientos empresariales, como condición necesaria para el desarrollo industrial del país. Desde esa postura, se constituye en un retroceso cualitativo en cuanto a su fortalecimiento como organización laboral, pues no sólo renuncia al involucramiento en el ámbito productivo, sino que negocia las concesiones laborales que le dan su fortaleza y legitimidad. En tanto que, el sindicalismo tradicional podría definirse como la organización laboral inserta en una burocracia sindical, que busca su permanencia como interlocutor laboral en una fase de reestructuración industrial, mediante el mantenimiento del control del mercado laboral y la práctica de una negociación contractual limitada por condicionantes laborales regionales. En esta acepción, la persistencia sindical se explica por la conservación de los preceptos mínimos de legitimidad entre sus bases.

4 Las industrias estables, con buena solvencia económica y con un lugar importante dentro del esquema productivo mundial, y con un funcionamiento más parecido a la industria tradicional, como podrían ser Deltrónicos de Matamoros, Thopson de Ciudad Juárez, favorecen el funcionamiento de un sindicalismo tradicional. En tanto que las industrias con escasa solvencia económica y con una alta supeditación a los cambios productivos internacionales y dominados por patrón de relaciones laborales, desde sus matrices y en sus distintas ramales mundiales, en donde se excluye al sindicato, favorecen el florecimiento del sindicalismo subordinado. 
misma categoría de análisis, ${ }^{5}$ sino que presentan rasgos diferenciadores que no pueden obviarse. En el caso del sindicalismo subordinado, sus variantes pueden fluctuar desde la vinculación mínima con sus representados, que le da cierta semejanza con el sindicalismo tradicional, hasta la subordinación total al empresariado, que le da más una connotación de instrumento de explotación que de defensor laboral. ${ }^{6}$

Los estudios realizados hasta ahora parecerían indicar que el sindicalismo subordinado y el tradicional son posturas excluyentes. Empero, el sindicalismo juarense parece ser la ejemplificación de un comportamiento sindical en donde se entrecruzan ambas variantes. Sin embargo, dado el predominio de las características subordinadas, para efectos del análisis realizado, queda inserto en esta última tipología. A continuación, postulamos cómo la trayectoria histórica premaquiladora puede ayudar a entender no sólo las diferenciaciones entre las dos alternativas sindicales más importantes, sino los matices existentes al interior de cada una de ellas.

\section{LA HISTORIA INDUSTRIAL Y SINDICAL PREMAQUILADORA}

Existe una íntima relación entre la historia local y el tipo sindical adoptado. Los estudios anteriores muestran los siguientes lugares como propicios para el sindicalismo subordinado: primero, emerge en localidades con una trayectoria sindical no consolidada debido al faccionalismo sindical (como Tijuana, Baja California); segundo, se produce en espacios con escasa trayectoria industrial y sindical, como es el caso de Nogales, Sonora. Por último, surge en localidades con una trayectoria sindical basada en el conformismo y la apatía que han sido incapaces de conformar una instancia sindical fuerte y hegemónica, como es el caso de Ciudad Juárez, Chihuahua.

5 El sindicalismo subordinado tiene entre sus características empíricas: la protección gubernamental por parte de instituciones laborales locales, como las juntas de conciliación, a cambio de su colaboración al proyecto de desarrollo nacional; el abandono del contrato colectivo como forma de negociación laboral y/o la aceptación de una flexibilidad contractual sin restricciones, una actitud pasiva ante los requerimientos producivos actuales y una actitud parcial o total de sus agremiados. En tanto que, el sindicalismo tradiconal lo caracteriza su persistencia en regiones con una trayectoria sindical consolidada y fuerte y la negociación de salarios y prestaciones, a través del contrato colectivo.

6 El sindicalismo subordinado pertenece a la estructura sindical oficial; comparte con ella la mayor parte de características, especialmente negativas, que se le ha asignado a este tipo sindical: vinculación mayor a la esfera política, ausencia de vida sindical, liderazgos colaboracionistas, etcétera. No se relaciona con alguna central obrera en particular sino que más bien es un tipo de política sindical al que se adhieren organizaciones laborales que sin ningún proyecto sindical definido, pretenden seguir vigentes en algunas industrias claves de la reestructuración industrial mexicana. 
Esta localidad comparte una historia similar a otras ciudades fronterizas mexicanas que fueron estimuladas por actividades turísticas y comerciales generadas por su cercanía con Estados Unidos. En especial, habría que mencionar el impacto que esta cercanía tuvo durante los años veinte y treinta con la la ley seca dictada en varias partes de Estados Unidos, ${ }^{7}$ y que en 1920 daría lugar a la Ley Volstead, y el establecimiento de maquiladoras a mediados de los años sesenta.

Otros elementos que han participado de manera activa en la economía juarense han sido: su pertenencia, y a veces no pertenencia, a las llamadas zonas o perímetros libres, dictadas por el gobierno mexicano para ayudar a los fronterizos a adquirir los productos necesarios que no puede ofrecerles el país; ${ }^{8}$ la cercanía con uno de los fuertes militares (Fort Bliss) construido durante la guerra entre México y Estados Unidos, que ha tenido más participación en las distintas etapas de la historia militar de Estados Unidos y que más ha estimulado la economía juarense; y finalmente, el haberse convertido en albergue perenne de la mano de obra desocupada en épocas de crisis económicas en el vecino país del norte.

La cercanía de los Estados Unidos y los factores enunciados conformaron una economía terciarizada, dependiente de los vaivenes económicos estadounidenses, en especial los que más impactaban a El Paso, Texas. El comercio y los servicios no sólo fueron la actividad hegemónica, sino que también propiciaron la primera gran fase de urbanización de la ciudad; la segunda se registraría con las maquiladoras. ${ }^{9}$ A los establecimientos más importantes, como el Tivoli Gardens, se les impusieron fuertes cargas impositivas que sirvieron para obras materiales del municipio.

Por último, habría que señalar que en el inicio de la terciarización juarense existió una rara amalgama entre actividades comerciales y turísticas lícitas e ilícitas. A partir de los años cuarenta y cincuenta se fomentaron más las actividades desprendidas del turismo - como la prestación de servicios-que las actividades comerciales. La cifras censales evidencian que de 1940 a 1990 existió un desarrollo mayor de los servicios en comparación con las actividades comerciales.

7 En Texas se implantó la ley seca el 15 de abril de 1918. Mediante esta legislación se eliminaron 250 clubes y cantinas en El Paso, Texas, así como 50 tiendas de licores y otros establecimientos relacionados con esta actividad. Algunos autores han seffalado que, gran parte de estos comercios se trasladaron a Ciudad Juárez propiciando un fuerte auge económico Martínez, 1982:85-110).

8 La discusión más completa e interesante sobre el impacto que la política de zona libre ha tenido en la economía juarense ha sido desarrollada por el profesor Oscar Martínez en su libro sobre Ciudad Juárez (Martínez, 1982).

9 Para una discusión más profunda sobre la evolución urbana de Ciudad Juárez vid. César Fuentes, "Análisis de la estructura urbana en Ciudad Juárez, Chihuahua" (1993). 
Aunque existieron otras actividades como la agricultura, el dominio del sector terciario fue incuestionable hasta 1970. Según los datos censales de 1940 a 1970, más de 50\% de la población económicamente activa (PEA) de Ciudad Juárez, estaba concentrada en actividades terciarias. La introducción de plantas maquiladoras en las ciudades fronterizas a mediados de los años sesenta, permitió que el sector secundario se convirtiera en un contrapeso del sector terciario.

Los datos censales de 1980 muestran que $28.7 \%$ y $36.6 \%$ de la PEA juarense se encontraba en el sector secundario, en especial en la industria de transformación (maquiladoras, $21.6 \%$ ) y el terciario, respectivamente. En 1990, la actividad industrial logro desplazar al sector terciario cuando el censo reportó que $49.2 \%$ estaba en el sector secundario, y $45 \%$ en el terciario (SPP, 1983:110; INEGI, 1992).

La trayectoria industrial de Ciudad Juárez se inició en 1966 con la implantación del Programa de Industrialización Fronteriza, mediante el cual se buscaba crear empleos para los trabajadores desocupados por la terminación del Programa Bracero de 1942. En ese año, las estadísticas mostraron que se habían establecido cinco empresas que daban empleo a 760 trabajadores. A partir de entonces, y en virtud del apoyo del gobierno en sus distintos niveles y los empresarios locales, la evolución de la industria maquiladora no ha cesado. En 1994 daba empleo a 147072 trabajadores (INEGI, 1995).

Ahora bien, a la par del desarrollo económico descrito, se fueron constituyendo los distintos sindicatos. Dada la importancia del sector turismo, los primeros sindicatos en surgir fueron los vinculados con estas actividades, tales como los de los meseros y los músicos. Algunos datos evidencian que Ciudad Juárez no pudo escapar al dominio de las grandes centrales obreras de la época, como lo muestra la participación activa de la Confederación Regional Obrero Mexicana (CROM) durante algunos actos de protesta de los años veinte y treinta para proteger a las actividades locales (Martínez, 1982: 96). ${ }^{10}$ Un caso excepcional dentro del sindicalismo juarense lo constituyó el Sindicato de Panaderos, que a finales de los veinte y durante la década de los treinta, escenificó fuertes movilizaciones por firma de contrato colectivo, pago de acuerdo con el tipo de pan realizado y cumplimiento del descanso dominical (El continental, 5 de noviembre de 1935:1).

${ }^{10}$ Rocío Guadarrama ha señalado que en Ciudad Juárez la CROM tenía afiliados, desde diciembre de 1926, a los miembros de la Liga de Resistencia Agrarista Jimenense Emiliano Zapata y la Unión de Empleados de Hoteles, Restaurantes y Cantinas, (Rocío Guadarrama, s/f:198-199). 
A pesar de haber tenido un desarrollo temprano, los sindicatos juarenses nunca lograron consolidarse como una fuerza social, aunque formalmente estuvieron unidos mediante su pertenencia a la Cámara Sindical Obrera, que funciono en los años veinte y treinta. La cercanía con Estados Unidos tuvo efectos contraproducentes para la fortaleza sindical. Ésta quedó sujeta a los vaivenes económicos de Estados Unidos y a las medidas económicas que se dictaban desde el centro para Ciudad Juárez. Esta dependencia impidió a los sindicalistas contar con una fuente laboral estable, así como realizar un trabajo sindical continuo.

Otros factores, como el regreso de mexicanos desocupados en épocas de crisis de la economía estadounidense habrían de impactar de manera negativa en la organización de ambos lados de la frontera juarense. La sobreoferta de mano de obra representó una válvula que permitía mantener la mayor parte de las actividades sin sindicatos. La llegada de nuevas centrales sindicales que absorbieron a los antiguos sindicatos cromistas como la CTM, que desde finales de los años cincuenta se convirtió en la central hegemónica de Ciudad Juárez, o se introdujeron en sectores no sindicalizados, como la Confederación Regional Obrero Campesina (CROC) en los años cincuenta y la excelente organización empresarial existente, habrían de complejizar más el panorama sindical juarense. Las características economicas y sindicales premaquiladoras constituyen el preámbulo necesario para entender la debilitación y supeditación sindical actual en las maquiladoras.

\section{EL SINDICALISMO MAQUILADOR JUARENSE}

Este apartado señala las principales características que han distinguido al sindicalismo juarense al interior de las maquiladoras. La llegada de las primeras maquiladoras pareció no representar ningún problema para las centrales de la época. La CTM, central más importante, se introdujo en algunas de las primeras plantas; en ellas firmó un contrato colectivo parecido a los que regían en otras negociaciones cetemistas. ${ }^{11}$

\section{El sindicalismo oficial: faccionalismo y derrotas laborales}

La política sindical cetemista inicial estuvo caracterizada por la firma del contrato colectivo y su revisión subsecuente para lograr mejores salarios

\footnotetext{
${ }^{11}$ Debido a la ausencia de una organización capaz de absorber a esta actividad, se creó el Sindicato de Trabajadores de la Industria Maquiladora-CTM para agrupar a las distintas maquiladoras.
} 
y prestaciones. La diferencia central que se registró en la negociación de los primeros contratos colectivos no provino de la calidad industrial de las empresas, sino de las demandas sindicales tradicionales.

Dada la especialización de las primeras plantas maquiladoras, la CTM propugnó por el pago del salario profesional. Petición que logró en la rama textil. Los líderes expresaron en 1975, que más de 4000 trabajadoras de las maquiladoras textiles recibían el pago de salario profesional ( $\mathrm{El} \mathrm{Co}$ rreo, 6 de junio de 1975). Se podría postular que entre el inicio maquilador (1966) y 1974 existió un dominio incuestionable de la СТM en la rama maquiladora, propiciado especialmente por la existencia de un férreo liderazgo en la persona de Roberto Delgado Urías ${ }^{12}$ y la consecución de algunas conquistas laborales en las primeras negociaciones contractuales. Según algunos analistas, durante la administración de Delgado Urías, la СTM lleg6 a contar con $65 \%$ de los trabajadores sindicalizados en las maquiladoras (Carrillo, 1985:143). La importancia cetemista, adquirida por su éxito inicial en las maquiladoras, se extendió a otros sectores económicos de la localidad. ${ }^{13}$ Sin embargo, dos elementos habrían de frenar el poderío inicial cetemista: las pugnas intracetemistas y la competencia agresiva de la CROC por contratos colectivos en las maquiladoras.

Después de dos décadas de liderazgo ininternumpido, Roberto Delgado Urías comenzó a experimentar fuertes cuestionamientos. En 1977, el líder fue removido de su cargo por "malversación de fondos, privilegio de intereses personales sobre los laborales, por la utilización de golpeadores de trabajadores disidentes y de traición al movimiento obrero". ${ }^{14}$

En la remoción se podrían distinguir elementos internos y externos. Los primeros estuvieron representados por la presión del grupo denominado "Movimiento Reivindicador de la Dignidad de la Federación de Trabajadores del Norte", encabezado por José Sosa y Manuel Cota, que

\footnotetext{
12 Roberto Delgado se inició como miembro del sindicato de panaderos, en donde se distinguió como uno de los militantes más activos. A finales de los años cincuenta fue elegido secretario general de la CTM juarense, apoyado en su calidad de excelente orador y negociador, Delgado Urías fue consiguiendo una fuerte ascendencia entre los trabajadores juarenses, logrando ser reelecto en varios periodos. Durante su administración la CTM logró contabilizar 60 sindicatos que agrupaban alrededor de 60000 miembros. Su poderío se extendió hasta 1977 , año en el que fue removido.

${ }^{13}$ En 1972, el dirigente cetemista expresaba que se habían afiliado 15 nuevos sindicatos, con lo que se llegaba a una membresía de 80 . Esto se debía a que “...la central ha llevado a cabo una inmensa campaña de afiliación con el fin de que los trabajadores libres integren gremios que puedan defender sus derechos con las mayores probabilidades de éxito...", (El fronterizo, 8 de agosto de 1972).

${ }^{14}$ Entrevista a Luis Parra, exsecretario de la FTCJ-CTM, realizada en noviembre de 1995.
} 
propugnaba por el "saneamiento de la Federación de Trabajadores del Norte y proteger realmente los intereses de sus sindicatos agremiados" ( $E l$ fronterizo, 8 de febrero de 1976), se consideraba que se había llegado a un punto en donde "el dirigente consideraba la organización como propiedad suya". Los externos, para avalar el cambio, estuvieron representados por la participación directa de Fidel Velázquez. El conflicto terminó con la remoción y la expulsión de Delgado Urías y el nombramiento de José Sosa como nuevo secretario general. ${ }^{15}$ No obstante, la solución adoptada fue momentánea, pues al interior del cetemismo juarense siguió latente el faccionalismo. 16

Recientemente, después de un periodo de aparente calma, los conflictos volvieron a aflorar cuando la mayor parte de los secretarios generales cetemistas exigieron la renuncia de Luis Parra, dirigente en los últimos años, en virtud de "que no había convocado a las elecciones previstas". 17 Otros dirigentes han expresado que la movilización se debió a que "Don Luis bajo la guardia, se sintió la pasividad de Don Luis que se atribuía a su edad y enfermedad". ${ }^{18}$ En unas elecciones por demás accidentadas, se nombró como nuevo dirigente al diputado Jesús José Díaz Monárrez. ${ }^{19}$ Empero, la no pertenencia del diputado Díaz a ninguna organización obrera, a pesar de sus objetivos y su inicio impresionante ${ }^{20}$ parecía anunciar nuevas controversias al interior del organismo cetemista tanto a nivel local, como estatal.

\footnotetext{
15 José Sosa Delgado, el nuevo dirigente cetemista, era miembro activo del Sindicato de Meseros de Ciudad Juárez. En este sindicato se había distinguido como militante y también había desempeñado el cargo de secretario general, (El fronterizo, 30 de diciembre de 1976.

16 José Sosa sólo duró un año y medio debido a que "no se siguieron los objetivos previstos con el cambio de Roberto Delgado"; después se eligió a Jacobo Valenzuela que duró menos. Finalmente, la inestabilidad cesa con el nombramiento interino de Luis Parra Orozco como secretario general. Parra Orozco había sido enviado de la Federación Estatal en Chihuahua. Después de este interinato, Luis Parra fue nombrado como dirigente formal de la CTM-juarense, (E.J.D., mayo, 1996).

17 Luis Parra, después de cumplir con su administración de tres años - sin contar el año y medio del interinato- prorrogó las elecciones de un nuevo líder cerca de dos años más. Esta situación incomodó a los otros secretarios generales, quienes solicitaron la intervención de la Federación Estatal (E.J.D., junio de 1996).

${ }_{18}$ Entrevista realizada en junio de 1996 a Jesús José Díaz M., secretario de la FTJC-CTM.

19 Parra Orozco aceptó su remoción sin cuestionamiento cuando constató que la mayor parte de los secretarios solicitaban su remoción. El nuevo dirigente fue electo en una asamblea de 42 secretarios generales juarenses, de 65 que conforman la CTM, con 38 votos por 4 en contra. En la elección contó con el fuerte respaldo de Antonio Ruvalcaba, principal dirigente de los quince sindicatos de autotransportes.

${ }^{20}$ El nuevo dirigente logró conformar un comité ejecutivo que integró diferentes facciones sindicales. Además, ha logrado que antiguos sindicalistas, como Isela Torres, retornen a la CTM. También integró tres nuevos sindicatos a la CTM y busca nuevas alternativas, evitando los errores anteriores, para sindicalizar las maquiladoras.
} 
El faccionalismo en los gremios laborales y la ausencia de una política de resistencia ante las empresas, condujo a fuertes derrotas sindicales a mediados de los años setenta, que minaron aún más la presencia de estas organizaciones en la localidad. En esta década, la CTM enfrentó fuertes problemas en las maquiladoras al demandar la firma y/o el respeto del contrato colectivo éstas; aumentos salariales y pago de la indemnización correspondiente en caso de que las empresas se vieran obligadas a cerrar por problemas económicos. Estos enfrentamientos constituyeron el movil central para su debilitamiento total en estas plantas. ${ }^{21}$

Un último factor acentuaría el declive cetemista: la competencia desleal de la CROC en cuanto a la firma de contratos colectivos.

$\mathrm{Al}$ iniciarse los setenta, y como reacción al fortalecimiento que la CTM había tenido en los inicios de las maquiladoras, el cual había contemplado incluso la reafiliación de negociaciones que ya estaban sindicalizadas con otras centrales (El fronterizo, 14 de enero de 1973), la CROC inició una agresiva campaña en contra de la CTM.

Esta lucha intersindical, si bien se extendió a distintos sectores, fue especialmente aguda en las maquiladoras. Movimientos como Acapulco Fashion (1969) y Toko (1974), muestran una disputa por el dominio del contrato colectivo. El objetivo principal, más que defender a los trabajadores, fue consolidar una hegemonía sindical en este sector, lo que provocó la politización del conflicto. En varias de estas luchas, los derechos laborales fueron olvidados y los trabajadores utilizados según conviniera a los intereses sindicales, abandonándolos en caso de que la situación se complicara. Más aún, cuando existieron represalias, los trabajadores fueron quienes pagaron los costos al ser despedidos o reprimidos.

En su campaña por conseguir más afiliados, la CROC utilizó diversas tácticas: desde la acusación abierta de que la СтM era "una sociedad de patrones", 22 hasta el ofrecimiento de "contratos de protección" a los

${ }^{21}$ Los años de 1974 y 1975 se pueden considerar como el inicio formal del declive cetemista en las maquiladoras. En ese año, la CTM emplazó a huelga a varias empresas demandando aumento salarial, con la finalidad de recuperar el poder adquisitivo y mejores condiciones de los trabajadores. En esos años, la CTM enfrentó conflictos laborales en cerca de 25 maquiladoras, entre las que estuvieron Famex de Ciudad Juárez, Transformex, Componentes, Inc. de México, Ampex, Cintas Magnéticas, Admiral de México, Advance Boss de México, Textiles Industriales, Calzado y Avíos, S.A. y otras. Estas demandas sindicales y la escasa solvencia económica de algunas maquiladoras, creó un ambiente laboral difícil que desembocó en el cierre de decenas de plantas. Los empresarios culparon de esta situación a la CTM, a quien acusaron de obstaculizar el desarrollo juarense y "presionar a las empresas", sin tener en cuenta sus problemas económicos, (vid. El correo, 1974-1975).

22 El dirigente croquista se refería a las características tan especiales de algunos sindicatos cetemistas del rubro terciario, en donde estaban afiliados propietarios de automóviles de sitio, dueños de peluquerías, comerciantes ambulantes, etcétera, que explotaban "a sus trabajadores, al no pagarle sueldo mínimo" (El fronterizo, 4 de febrero de 1972) 
empresarios. Especialmente, esta última táctica fue el principal detonante de algunos de los enfrentamientos entre la CTM y la CROC. Dentro de estos conflictos, en donde muchas veces existió una participación real de los trabajadores, podrían citarse los casos de Essex International de Chihuahua (1973), Toko, S.A. (1974) y Molduras de Pino, S.A. (1975).

En todas las empresas anteriores, la CROC fue acusada de tener firmados contratos colectivos leoninos, por lo que los trabajadores se movilizaron en demanda de una organización más representativa de sus intereses. En estos movimientos, se recurrí a la CTM como una posible alternativa a su problemática. No obstante, la exigencia de demandas laborales tradicionales, con un margen muy escaso de negociación, la poca solvencia de algunas plantas y el apoyo abierto de los empresarios a la CROC, impidieron cualquier intento de sindicalización más representativa.

Un balance de las luchas sindicales de la década de los setenta permite observar el debilitamiento de la CTM-juarense propiciada por el rechazo de su política tradicional, ${ }^{23}$ la prefencia de la política colaboracionista y no conflictiva de la $\mathrm{CROC}^{24}$ y la pérdida del control local de importantes maquiladoras como la RCA, que más tarde recuperaría.

Por el lado contrario, a partir de mediados de los setenta, se observó en Ciudad Juárez un fortalecimiento constante de la CROC. Esta central, a finales de 1975, según sus dirigentes, contaba con 8000 miembros, entre los cuales se encontraban los trabajadores de las maquiladoras Acapulco Fashion, Centralab, Canyon, Essex, Karen y Coilcraff, (El fronterizo, 11 de diciembre de 1975). Gran parte de los contratos habían sido obtenidos en virtud del sindicalismo de membrete que ofrecía la CROC, así como por su irrestricto apoyo al empresario. ${ }^{25}$ Mientras la CTM exigía aumentos salariales, la CROC expresaba que:

[...] el aumento de salarios sólo traería alza de precios de los artículos de primera necesidad, por lo que, acordamos no acatar el

\footnotetext{
${ }^{23}$ Pese a las derrotas sufridas en los años setenta por sus demandas sindicales, los dirigentes no variaron su política y continuaron denunciando las violaciones laborales de la maquila y la supuesta apatía de los trabajadores para sindicalizarse, según su expresar “...los trabajadores no se han decidido aún a unirse para defender sus derechos legales y exigir un trato humano y respetuoso...", (El Correo, 18 de enero de 1980).

${ }^{24}$ Según algunos analistas, la firma del contrato colectivo de Acapulco Fashion en 1969, "marcaba el inicio de una serie de beneficios que esta central ofrecía a las empresas para que lograran un mayor control de sus trabajadores. También abría la posibilidad de una política de común acuerdo entre empresa y sindicato", (Carrillo, 1985:140).

${ }^{25}$ Esta política de apoyo empresarial no era novedosa, se había empezado a practicar desde principios de los sesenta, cuando trabajadores croquistas se ampararon en contra de un impuesto del $1 \%$, fijado al empresario para apoyar a la educación media y superior. Los sindicalistas de la época denominaron a esta acción como "vergonzante del movimiento obrero y retrograda para el desarrollo de México", (El fronterizo, 19 de febrero de 1963).
} 
ordenamiento del Congreso del Trabajo (en cuanto al incremento salarial)[...] y no participaremos en los emplazamientos de huelga que organiza la CTM a nivel nacional[...] (El fronterizo, 17 de agosto de 1974).

El conformismo ha sido una de las principales características del sindicalismo croquista en Ciudad Juárez. El cuestionamiento o la exigencia de mejores condiciones salariales y laborales han sido eliminadas de sus negociaciones. Según los dirigentes croquistas, no tiene caso exigir, pues "si las empresas pueden aumentar beneficios lo harán y si no pueden no lo harán", aunque existan peticiones (El fronterizo, 7 de mayo de 1975). Este conformismo y apatía ha acentuado aún más la debilidad sindical en las maquiladoras, pues a pesar de estar sindicalizadas ciertas plantas, con esta política es como si no lo estuvieran.

[...] la debilidad sindical se debe a la competencia desleal y la política sindical, que mantienen los empresarios con otras centrales, por ejemplo: "la CROC vende contratos que aceptan los ajustes salariales mínimos[...] (los patrones) compran a la dirigencia sindical para controlar a los trabajadores. Además si alguien pregunta (en estos sindicatos) por sus derechos 'va para afuera' de la CROC[...] algunos Comités de la CROC recurren a utilizar a los empleados de confianza, en caso de problemas sindicales, haciéndolos pasar como trabajadores" 26

Para efectos de la hipótesis manejada en este texto, en torno de la vinculacion entre historia y comportamiento sindical, habría que mencionar la persistencia y anquilosamiento que existio en la CTM durante casi dos décadas de sindicalismo maquilador. Mientras la CROC, para recuperar terreno optó por una política de conformismo y no cuestionamiento, la CTM, a pesar de las continuas derrotas, continuó exponiéndose a nuevos reveses al seguir demandando las peticiones tradicionales sin ofrecer ninguna alternativa que permitiera una negociación con las maquiladoras. En 1983, año de una profunda crisis económica, la СTM enfrentó fuertes problemas laborales en Fluorex, Homes International, Sistemas Electrónicos y Conmutadores, y otras que habrían de modificar su comportamiento, como explicaremos más adelante. Las demandas principales fueron por reinstalación y el pago de las indemnizaciones correspondientes. ${ }^{27}$ En algunas maquiladoras la CTM obtuvo lo mínimo; en otras fue derrotada.

\footnotetext{
${ }^{26}$ Entrevista realizada en noviembre de 1995 a Luis Parra, ex secretario de la FTSC-CTM.

27 La CROC no permaneció ajena a esta crisis, como lo muestran los conflictos experimentados en Acapulco Fashión y Spectronies. No obstante, lejos de reclamar algún beneficio para sus agremiados, acentuó su conformismo y los abandonó a su suerte.
} 
A manera de corolario, habría que mencionar también la persistencia de viejos vicios sindicales entre el liderazgo cetemista, como podría ser el comportamiento corrupto de sus dirigentes al interior de las maquiladoras. Algunos ejemplos de esta situación han sido los siguientes: Subensambles Electrónicos de Ciudad Juárez, S.A, en donde se exigió la renuncia de la secretaria general, Dora Villegas, por la no defensa de los trabajadores $(E l$ fronterizo, febrero de 1976); RCA, quien denunci6 el control y el hostigamiento de Genaro Ricarte, líder por 17 años, hacia los trabajadores y el colaboracionismo tan cercano entre empresa y dirigente (El fronterizo, 31 de octubre de 1986); y más recientemente en la misma RCA, en donde se acusó al dirigente Cruz Méndez Olivas, de "no apoyar las peticiones de los trabajadores" y de tener tratos con la empresa, (Diario de Juárez, enero-febrero 1995). ${ }^{28}$

\section{El sindicalismo independiente: una experiencia infructuosa}

Los vicios del sindicalismo oficial enunciados, así como las constantes derrotas cetemistas, han fermentado en Ciudad Juárez un movimiento obrero de tipo independiente, como alternativa para conseguir las demandas que no han logrado por el sindicalismo oficial. Este apartado delinea algunas de las principales características de estos movimientos.

$\mathrm{El}$ análisis de las experiencias sindicales independientes se centra en dos manifestaciones centrales: la conformación de coaliciones obreras ${ }^{29}$ en lugar de sindicatos al interior de algunas empresas, y en el trabajo que han realizado algunas organizaciones, entre las que ha estado el Frente

\footnotetext{
${ }^{28} \mathrm{El}$ movimiento de la RCA, ahora denominada RCA Thopson, ha sido el último gran cuestionamiento que ha escenificado la CTM en Ciudad Juárez. En él, se vieron involucrados no sólo las cuatro plantas de Ciudad Juárez, con sus seis mil trabajadores, sino la planta de El Paso, Texas y su matriz en Indiana. En el conflicto se entremezcló la lucha por mejores condiciones salariales y el descontento con el liderazgo. En la resolución del problema tuvo una participación decisiva Doroteo Zapata, dirigente estatal de la CTM. A nivel local, y dado el descontento con el dirigente, más no con la CTM, el conflicto fue manejado por una coalición de trabajadores de la RCA Thopson. El movimiento, asombrosamente, desembocó en un triunfo de los trabajadores: $13 \%$ de aumento, pago de salarios caídos, compromiso de los directivos para no emprender actos de represión o despido en contra de los trabajadores participantes en el movimiento, nombramiento de un nuevo dirigente sindical y reconocimiento de la coalición hasta que no se elija el nuevo dirigente, (Diario de Juárez, 8 de febrero de 1995).

29 La Ley Federal del Trabajo mexicana expresa: "La Ley reconoce la libertad de coalición de trabajadores y patrones" (art. 354), y define la coalición como: "El acuerdo temporal de un grupo de trabajadores o de patrones para la defensa de sus intereses comunes" (art. 355). Por otro lado, la constante utilización de este recurso por los obreros juarenses, especialmente en las huelgas, parece estar desprendido del artículo 440, en donde se expresa: "Huelga es la suspensión temporal del trabajo llevado a cabo por una coalición de trabajadores". Más adelante, la misma ley expresa: "Para los efectos de este título, los sindicatos de
} 
Auténtico del Trabajo (FAT) ${ }^{30}$ y los intentos de algunas organizaciones sindicales estadounidenses a partir de 1994, para conformar sindicatos independientes. ${ }^{31}$ En cuanto al primer punto, se puede señalar que la recurrencia a la coalición puede estar basada en una supuesta mayor posibilidad para triunfar en los movimientos laborales al no tener los vicios del sindicato, ni sus ataduras legales. Pese a estas previsiones, dichas acciones de los trabajadores no han tenido éxito.

La recurrencia a las coaliciones se inicia a mediados de los años ochenta: la estrategia ha sido utilizada en las luchas de Banda Grande, AMF, Texcan de México y Cupones de Oro; todos escenificados en 1986. Las peticiones de las coaliciones, la mayoría de las veces, fueron por despido injustificado o por cierre de plantas y surgieron, principalmente, en maquiladoras pequeñas. Exceptuando el caso de Cupones de Oro, que podría considerarse el prototipo de la lucha laboral mediante coalición, la mayor parte de los movimientos fueron derrotados o consiguieron muy poco en su lucha. En estas acciones, la no claridad del estatus organizativo de los movimientos, propiciaron una actuación ambigua de la Junta Local de Conciliación y Arbitraje de la Asociación de Maquiladoras, e incluso de los sindicatos oficiales.

A pesar de estas derrotas, se ha seguido recurriendo a las coaliciones, como lo demostró el caso de RCA en 1995. Según un reporte, entre 1988 y 1995 se registraron 49 huelgas, de las cuales $81.63 \%$ fueron promovidas por coaliciones independientes; sólo $18.36 \%$ de las huelgas fueron realizadas por la CTM, que cuenta con 65 sindicatos y más de 20000 trabajadores; y la CROC, con 25 empresas y alrededor de 15500 miembros, no estallo ninguna huelga, según Luis Vidal, su líder, "porque no hubo necesidad" (Diario de Juárez, 17 de febrero de 1995).

La otra experiencia por un sindicalismo independiente ha sido a través de la búsqueda de registro de organizaciones sindicales independientes.

trabajadores son coaliciones permanentes" (art. 441). A reserva de estudiar más detenidamente la recurrencia a coaliciones en Ciudad Juárez, podría postularse la influencia del abogado Gustavo de la Rosa para utilizar este recurso y poder obtener una victoria; así lo demuestran sus declaraciones y su asesoramiento en la mayor parte de los movimiento de este tipo. Además habría que mencionar este tipo de organización como previa a la constitución de un sindicato formal.

${ }^{30}$ Según Pedro Serna, dirigente del Centro Patronal del Norte, en 1974 el FAT estaba ganándole terreno al sindicalismo oficial. En ese momento, “...la FAT organiza a los trabajadores en sindicatos independientes y les presta asesoramiento jurídico, laboral, capacitación sindical y organizacional. La fuerza de la FAT está representada por más de 50 000 trabajadores afiliados a no menos de 50 organizaciones...", (El fronterizo, 6 de agosto de 1974).

${ }^{31}$ El movimiento sindical independiente y sus principales expresiones en Ciudad Juárez, están por estudiarse. En este artículo únicamente se enuncian algunos de los rasgos que han caracterizado las luchas independientes. 
Esta estrategia ha estado presente en Ciudad Juárez desde hace dos décadas. Los intentos de sindicalización independientes que más resonancia han tenido son los casos de Vitroformas, s.A. de c.V. (1975), AMF (1976), Admiral de México, S.A., (1976) Acapulco Fashion (1978), Texcan (1983), Vestamex, Camisas de Juárez (1987), General Electric (1993), Autopartes y Arneses, S.A (1995). Invariablemente, la lucha por el reconocimiento de organizaciones independientes fue para conformar representaciones laborales más relacionadas y comprometidas con las necesidades obreras.

A diferencia de los movimientos por coaliciones, la respuesta a las luchas independientes ha sido casi siempre la misma: despido de los organizadores, condena por parte de los organismos empresariales, rechazo por las centrales oficiales y las autoridades municipales, y la negación de su registro por parte de la Junta Local de Conciliación y Arbitraje de Ciudad Juárez. La derrota de los movimientos laborales por coaliciones y el fracaso en el registro de sindicatos independientes, ha debilitado aún más el sindicalismo juarense.

\section{La flexibilización sindical: consecuencia de la debilitación sindical}

Las derrotas sindicales, oficiales e independientes, la ausencia de liderazgos férreos y de una estrategia sindical para recuperar espacios, condujeron a las distintas centrales, especialmente a la CTM, a adoptar una política sindical conformista. Los líderes sindicales, en lugar de transformar su estructura y función o modificar sus estrategias de sindicalización para su reforzamiento, optaron por una conducta conformista y no cuestionadora, llegando a su punto máximo durante la administración de Luis Parra Orozco. El discurso del dirigente evidenciaba un conformismo acentuado:

[...] antes se hacía trabajo de ir a organizar a los trabajadores, ahora es distinto, no se sale a convencer a los obreros. Esto conduce a que no haya interés por parte de los trabajadores jóvenes, quienes desconocen lo que costó contar con los derechos laborales, que ahora tienen[...] Además, dado los problemas que se le causa al trabajador, se ha optado, algunas veces, por no inmiscuirse en las maquiladoras $[. . .]^{32}$

Las derrotas de los años ochenta, y las más recientes, muestran aún más este conformismo y no cuestionamiento. Paradojicamente, las acciones tan repudiadas fueron adoptadas como el recurso extremo para retener las

\footnotetext{
32 Entrevista realizada en noviembre de 1995 a Luis Parra, ex secretario de la FTCJ-CTM.
} 
pocas maquiladoras que aún estaban agremiadas al cetemismo. De esta manera, la flexibilidad y el colaboracionismo croquista tan criticado anteriormente, se convirtieron en la característica central del sindicalismo juarense actual. La prevista fortaleza, mayor agresividad y honestidad que habrá de caracterizar a una nueva Стм juarense, según su nuevo dirigente, está por verse; en este momento, la flexibilidad laboral ha impregnado los espacios fabriles más importantes.

La flexibilidad en Ciudad Juárez se ha distinguido por el cercenamiento de algunas cláusulas contractuales que le concedían una mayor participación a los sindicatos en la definición de condiciones laborales y en la ejecución del trabajo. Asimismo, los sindicatos juarenses han mantenido sus demandas salariales en el punto mínimo y han eslabonado las prestaciones conservadas a las necesidades de la producción. En este sentido, en Juárez existe una conducta que los diferencia de otros comportamientos subordinados: han sido las mismas centrales obreras, a través de los sindicatos locales tradicionales, las que han autocercenado sus contratos colectivos. $^{33}$

La debilidad sindical se ha traducido en el cercenamiento de conquistas laborales del sindicalismo tradicional que buscaba la estabilidad, la antigüedad, etcétera; en su lugar, se han estipulado prestaciones que incentivan la eficiencia y la calidad, privilegiando con ello más el interés empresarial que la búsqueda de beneficios para el trabajador. El éxito relativo que se ha conseguido en algunas empresas mediante esta flexibilización, erróneamente ha contribuido a que los sindicatos juarenses consideren que están contribuyendo al éxito maquilador. Empero, la supuesta participación en la elevación de la productividad se limita a la supeditación de las conquistas laborales a los requerimientos empresariales más que una política propositiva. $^{34}$

El pago a esta política sindical de cooperación o supeditación se ha dado a través de la conservación de las cuotas sindicales, derivadas de los tradicionales descuentos a obreros o el pago directo por parte de la empresa, situación que lo diferencia de otras variantes subordinadas y el mantenimiento de claúsulas contractuales, como la de exclusión, que

\footnotetext{
${ }^{33}$ Para una mayor profundización en el cercenamiento de los contratos colectivos juarenses, vid. María Eugenia de la $\mathrm{O}$ y Cirila Quintero, "Contratación colectiva en las maquiladoras fronterizas" (1993).

${ }^{34}$ María Eugenia de la $\mathrm{O}$ en su obra La industria maquiladora electrónica en México. El caso de Ciudad Juárez, (1995), ha analizado de manera excelente cómo la cтM ha ido cercenando sus propios contratos colectivos mediante el análisis del sindicato de la RCA de Ciudad Juárez, De la O muestra cómo, de 1979 a 1989, la CTM recortó gran parte de sus conquistas anteriores y supeditó gran parte de sus conquistas a las necesidades empresariales.
} 
garantizan el dominio sindical sobre los trabajadores. La legitimidad entre sus bases se convierte en un factor secundario.

Un elemento que habrá de agudizar más el debilitamiento sindical es el privilegio ascendente, que se está concediendo, tanto a nivel local como nacional, de la industrialización y la marginación de los derechos laborales. Los dirigentes sindicales tradicionales han expresado que este apoyo ha sido uno de los elementos más constantes que han conducido al debilitamiento de las organizaciones laborales:

\begin{abstract}
[...] la debilidad se debe a una política gubernamental que privilegia la inversión y concede poca protección a los trabajadores que laboran en la maquila. "Los obreros están desmoralizados porque han perdido muchas huelgas, también saben que si luchan por sus derechos, pueden perder su trabajo, además de que no pueden volver a ingresar en otra maquila. Esta protección gubernamental (también) ha conducido a que muchas fábricas hayan desaparecido (sin el menor problema) (E.L.CRT Ciudad Juárez, 1995).
\end{abstract}

El caso específico de Ciudad Juárez muestra que el cambio a un gobierno de oposición como el PAN, no siempre trae aparejado mejores condiciones salariales y laborales para los trabajadores. Más bien se advierte un mayor impulso a conformar una cultura de colaboración; situación que parece vislumbrar un debilitamiento mayor del sindicalismo tradicional y una consolidación del colaboracionismo sindical.

El gobierno juarense ha manifestado su beneplácito por las relaciones laborales que favorezcan la "competititividad y elevación de la productividad de las organizaciones juarenses" y que sea capaz de "elevar la calidad de vida de todos los juarenses". ${ }^{35}$ En esta política, la actuación sindical, en particular la de cuestionamiento y de defensora de los derechos trabajadores, parece no tener un lugar primordial.

\title{
CONCLUSIONES
}

La debilidad del sindicalismo juarense, en este momento, es producto de su historia industrial y sindical. La alta dependencia de la economía estadounidense ha propiciado un sindicalismo débil, carente de un trabajo consolidado y desprovisto de una política y estrategia sindical que le permita subsistir en este momento de apertura comercial. El faccionalismo intra e intersindical ha impedido la consolidación de liderazgos férreos y

35 Entrevista realizada en noviembre de 1995 a funcionarios de la Junta Local de Conciliación y Arbitraje. 
alianzas sindicales que permitan el fortalecimiento de este tipo de organización en la localidad juarense; por el contrario, han creado los contextos ideales para que las luchas y movimientos sindicales sean derrotados.

$\mathrm{El}$ privilegio de los intereses industriales y la búsqueda de desarrollo económico han marginado el mejoramiento de los derechos laborales de los trabajadores juarenses mediante la formalización de contratos colectivos, dando paso al estímulo a la productividad y eficiencia, a través de un sistema de remuneración altamente dependiente de los ciclos económicos de las empresas maquiladoras.

Finalmente, el conformismo, la apatía sindical y el fomento de una cultura laboral que exalta la colaboración y tiende a un funcionamiento fabril sin sindicatos, parece augurar un futuro preocupante para la existencia sindical pero también para los más de cien mil trabajadores ocupados en la maquila juarense, dada la inexistencia de una organización laboral independiente $u$ oficial consolidada que pueda garantizar, en el futuro, una relación laboral equilibrada entre empresa y trabajador. 


\section{BIBLIOGRAFIA}

CARRILLO, Jorge. 1985. Mujeres fronterizas en la industria maquiladora, SEP/CEFNOMEX, México.

- 1988. Dos décadas de sindicalismo maquilador. Tesis de maestría, FCPS, UNAM.

DE LA O, María Eugenia y Cirila Quintero. 1993. “Contratación colectiva en las maquiladoras fronterizas", Frontera norte, El Colegio de la Frontera Norte, Tijuana, septiembre-diciembre.

DE LA O, María Eugenia. 1995. La industria maquiladora electrónica en México. El caso de Ciudad Juárez, Miguel Ángel Porrúa, UAM, México.

FUENTES, César. 1993. "Análisis de la estructura urbana en Ciudad Juárez, Chih.”, mimeografiado, El Colegio de la Frontera NorteCiudad Juárez.

GAMBRILL, Mónica. 1990. "Sindicalismo en las maquiladoras de Tijuana. Regresión en prestaciones sociales” en Reestructuración industrial: las maquiladoras en la frontera México-Estados Unidos, CONACULTA. México.

GUADARRAMA, Rocío. s/f. Los sindicatos y la política en México: la CROM, 1918-1928.

INEGI. 1992. XI Censo de Población y Vivienda.

- 1995. Estadísticas de la industria maquiladora de exportación, octubre.

MARTÍNEZ, Óscar. 1982. Ciudad Juárez: el auge de una ciudad fronteriza a partir de 1848, FCE, México.

QUINTERO Ramírez, Cirila. 1992. Reestructuración sindical en las maquiladoras mexicanas, tesis de doctorado en sociología, El Colegio de México.

SPP. 1983. X Censo de Población y Vivienda.

WILLIAMS, Edward. 1992. The Unionization of the Maquiladora Industry: the Tamaulipan Case in Nacional Context, Institute for Regional Studies of Californias.

\section{Hemerografía}

Revisión sistemática de los diarios: El Correo, 1969-1980; El fronterizo, Diario de Ciudad Juárez, 1970-1986; Diario de Juárez, 1986-1995. 